\title{
Imagem e Cognição em Cena: um estudo com a relação Iconicidade/ Indexicalidade*
}

\begin{abstract}
RESUMO
Neste artigo, que tem como cenário o cotidiano permeado de imagens ou representações visuais que, de algum modo, compõem nossas imagens ou representações mentais, objetiva-se construir um pensamento crítico sobre o cenário mencionado e explicitar as operações mentais vinculadas às representações visuais quando estas oscilam, na semiose, entre a iconicidade e a indexicalidade. Assim, no percurso metodológico valer-se-á de Baudrillard, Virilio e Jameson, para compor o cenário, enquanto para refletir sobre as operações mentais a semiótica peirceana se faz pertinente, especialmente a Lógica Crítica e a Lei da Mente, sem deixar de buscar assentamento para algumas dessas idéias em Damásio. A relevância desta investigação está no fato de se tentar resgatar o papel das imagens para a cognição e, com isso, atenuar as especulações, as fantasias que se constroem em torno das imagens que invadem nosso olhar.
\end{abstract}

\section{PALAVRAS-CHAVE}

Imagem

Representação visual

Cognição

\section{ABSCTRACT}

In this paper which has as scenery the quotidian permeated with images or visual representations that compose, of any way, our mental images or mental representations, we intend to work out in detail one critical thought about the scenery and to explicit the mental operations with visual representations when they oscillate entre icon and index, with Baudrillard, Virilio, Jameson for constructing the scenery and the semiotic of the Charles Sanders Peirce, mainly Critical Logic and "The Law of the Mind", without leaving Damasio's ideas to discuss about the mental operations. It's relevant to emphasize the role of the images for the cognition and to decrease the speculation, the fantasies that are constructed about images and the relation among them.

\section{KEY WORDS}

Image

Visual representation

Cognition

\author{
Maria Ogécia Drigo \\ Professora do Programa de Pós-graduação em Comunicação e Cul- \\ tura da UNISO/SP/BR \\ maria.drigo@prof.uniso.br
}

$\mathbf{0}$ cotidiano das pessoas está permeado de imagens, objetos materiais, signos que representam nosso meio ambiente visual. Há estudiosos da comunicação que consideram as imagens encantadoras e outros que as menosprezam. Jean Baudrillard, Frederic Jameson e Paul Virilio, entre outros e sob diversas perspectivas discutem o papel das imagens nas sociedades contemporâneas.

Constatamos a necessidade de aprofundar os conhecimentos sobre leitura de "imagens" principalmente durante a realização da pesquisa "Publicidade de Rua/Contexto Urbano: que relação é essa, afinal?", concluída em 2008 e desenvolvida sob supervisão de Winfried Nöth, tendo contado, inclusive, com um estágio de pesquisa na Universidade de Kassel, Alemanha, sob os auspícios da FAPESP (junho a agosto-2008). Tal projeto de pós-doutorado nasceu por sugestão de Lucia Santaella de dar continuidade a uma das temá- 
ticas (publicidade de rua) do projeto Probral (DAAD/ Capes 2000-2004), coordenado por Lucia Santaella (Brasil) e Winfried Nöth (Alemanha), versando sobre um estudo comparativo intercultural do uso de palavra e imagem nas mídias. Os resultados desse projeto encontram-se hoje publicados em Santaella, Lucia e Nöth, Winfried. Palavra e imagem nas mídias. Um estudo intercultural. Belém: Editora Universitária UFPA, 2008. Deste modo, as reflexões que apresentamos se inserem nos primeiros estudos de um novo projeto de pesquisa - "Imagem e pensamento em cena"- , aprovado em julho de 2009, pela FAPESP.

\section{A imagem sintética, a imagem} numérica, a realidade virtual corresponde ao apogeu da 'desimaginação' da imagem. A virtualidade, ao nos fazer adentrar na imagem, recria uma imagem em três dimensões e abole a ilusão do passado e do futuro, por se dar em "tempo real".

Santaella e Nöth (2001, p. 15), em seus estudos sobre imagem, afirmam que estas podem ser divididas em dois domínios: o das imagens como representações visuais e o das imagens na nossa mente. Desenhos, pinturas, gravuras, fotografias e imagens cinematográficas, televisivas e holo e infográficas são representações visuais, enquanto as imagens que aparecem como visões, fantasias, imaginações, esquemas, modelos ou, em geral, como representações mentais, pertencem ao domínio das imagens da nossa mente.

A problemática que envolve as imagens, tanto nos processos comunicacionais como nas suas relações com a construção da realidade pelos leitores/usuários de signos, talvez tenha se acentuado porque as imagens não tiveram o mesmo tratamento dado à palavra. Desde a invenção da imprensa, como enfatiza Santaella (2001, p. 13), a palavra reina quase que absoluta nas pesquisas, quer sejam as realizadas pelos acadêmicos da gramática, da retórica ou da filologia, enquanto os estudos sobre imagem não estabeleceram uma tradição similar. As imagens, como expressão da cultura humana, antecedem ao registro da palavra pela escritura. Nas suas palavras:

Todavia, enquanto a propagação da palavra humana começou a adquirir dimensões galácticas já no século XV de Gutenberg, a galáxia imagética teria de esperar até o século XX para se desenvolver. Hoje, na idade do vídeo e infográfica, nossa vida cotidiana - desde a publicidade televisiva ao café da manhã até as últimas notícias no telejornal da meia-noite -, está permeada de mensagens visuais (Santaella, 2001, p. 13).

Santaella e Nöth, na introdução da obra "Imagem: cognição, semiótica, mídia" preconizam que uma "ciência da imagem, uma imagologia ou iconologia, ainda está por vir" (Santaella, 2001, p. 13). As investigações sobre imagens, segundo os autores, se distribuem por várias disciplinas de pesquisa, tais como história da arte, teorias antropológicas, sociológicas, psicológicas da arte, crítica da arte, estudos das mídias, semiótica visual, teorias da cognição.

Assim, após construir um breve panorama sobre imagem na perspectiva de Baudrillard, Virilio e Jameson, nos valemos de ideias peirceanas para refletir sobre as argumentações desses autores mencionados. A fundamentação se dará, portanto, com a semiótica peirceana, mais especificamente, com dois de seus ramos: a gramática especulativa e a lógica crítica, sendo que o primeiro trata do signo e de suas classificações - as inúmeras tricotomias -, e o segundo trata dos tipos de raciocínio. A lógica crítica necessita da gramática especulativa, pois todo pensamento se dá em signos. A semiótica ou lógica, em dois dos seus ramos, permite inventariar como as operações do pensamento se dão em meio aos diversos tipos de representações visuais, quando estas se fazem signos ou quase-signos. Algumas ideias que constam da Lei da Mente permitem esclarecer a relação entre qualidades de sentimento e o caminhar do pensamento.

Por fim, tais reflexões são pertinentes para a área, pois as imagens estão cada vez mais presentes no nosso cotidiano e a compreensão de como podem interferir, modificar ou conduzir operações mentais podem redimensionar a interpretabilidade de processos comunicacionais.

\section{Imagens em cena}

Baudrillard (1997) explica que o trompe l'oeil, pinturas presentes também em pinturas murais e de tetos 
no Renascimento e no Barroco, tornou-se "o protótipo do uso maléfico das aparências... um jogo que no século XVI toma dimensões fantásticas e termina por apagar os limites entre pintura, escultura, arquitetura"(p.20).

Essa tendência artística teve origens no século V a.C.. Nesse período, em Atenas, viviam dois artistas rivais: Zeuxis e Parrhasios. Na ocasião da disputa de um prêmio para o melhor trabalho de ilusionismo, Zeuxis produziu uma pintura com uvas com tal realismo, que pássaros se aproximavam do quadro para bicá-las. Ciente de que seu trabalho tratava do ilusionismo com perfeição, sugere ao concorrente, Parrhasios, que reproduzisse uma cortina que estava presente diante deles. Mas ao tentar tocar a cortina, Zeuxis constatou que fora enganado, uma vez que estava diante da pintura do seu concorrente.

Mas por que tal uso das aparências seria maléfico? Segundo Baudrillard (1997, p. 16), no caso das uvas de Zeuxis, há um excesso de realidade, o que é absurdo, pois não é no excesso que há milagre, mas na vertigem de nela perder-se.

Quando a organização hierárquica do espaço em proveito do olho e da visão, quando essa simulação perspectiva - pois não passa de um simulacro desfaz-se, outra coisa surge que, não dispondo de nada melhor, expressamos nas formas de tocar, de uma hiperpresença palpável das coisas, "como se pudéssemos pegá-las". Mas esse fantasma táctil não tem nada a ver com nosso sentido do tato; trata-se de uma metáfora da "surpresa" que corresponde à abolição da cena e do espaço representativo. (Baudrillard, 1997, p. 17-8)

Como explica o mesmo autor, tal surpresa nos revela que a "realidade" não é nada mais que um mundo encenado, que se objetiva de acordo com as regras da profundidade, "que ela é um princípio a partir de cuja observação regulam-se a pintura, a escultura e a arquitetura do tempo, mas um princípio somente, e um simulacro a que põe fim a hiper-simulação experimental do trompe- l'oeil'(Baudrillard, 1997, p.18).

Baudrillard toma como exemplo o studiolo em trompe-l'oeil de Montefeltre (Figura 1), de Federico de Montefeltro (1422-1482), duque de Urbino, da sua residência na cidade de Gubbio, ao norte de Perugia, Itália. O design do studiolo, que dá a ilusão de ser tridimensional, só foi possível pelo uso de um sistema linear de perspectiva criado pelo arquiteto Filippo Brunelleschi.

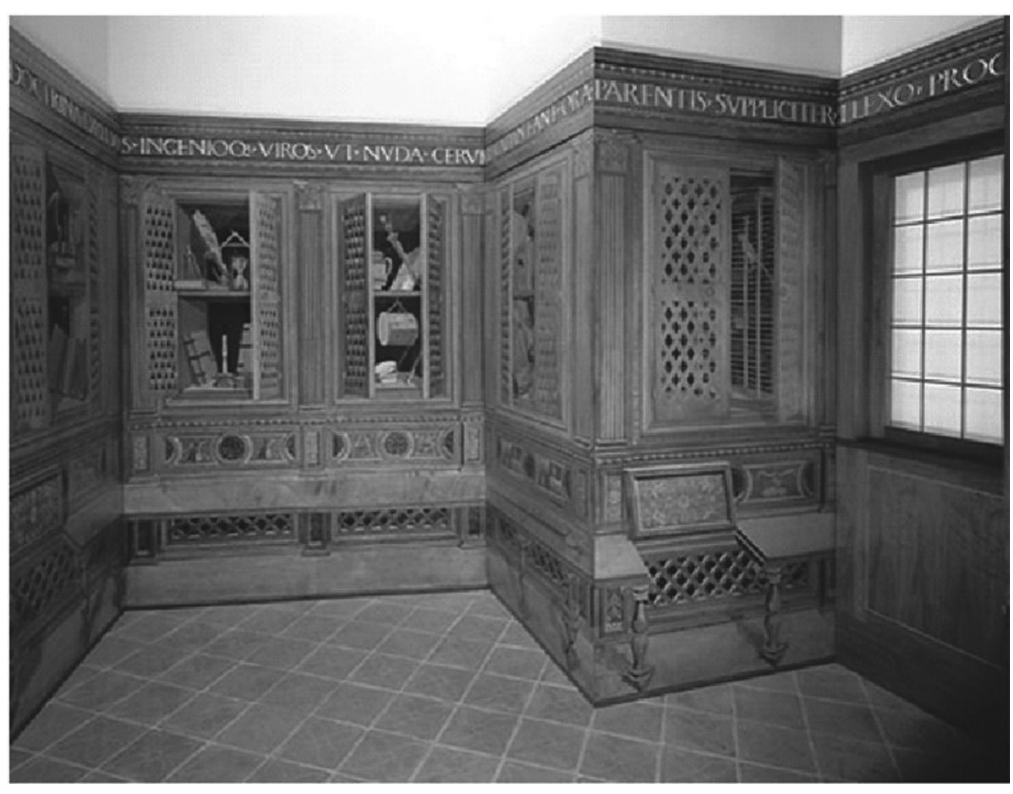

Figura 1 - Studiolo em trompe-l'oeil de Montefeltre ${ }^{1}$

Segundo o mesmo autor, a finalidade dessa técnica era tornar mais amplo, por exemplo, um ambiente fechado e estreito, por meio da ilusão da perspectiva, geralmente, direto na parede. As cores correspondem ao tema e aos materiais utilizados, como madeira, metal, pedra, mármores etc. $\mathrm{O}$ horizonte das paisagens pintadas coincide com o horizonte subjetivo de uma pessoa de altura normal (de 1,60 $\mathrm{m}$ a 1,70 m), enquanto o ponto de fuga corresponde ao melhor ponto de observação, por exemplo, a porta de entrada do ambiente, o que possibilita causar impacto assim que o observador se puser diante da pintura.

Ainda observando a pintura (Figura 1), na esteira de Baudrillard (1997, p. 18), estaríamos diante de um simulacro, construído em meio aos jogos e artifícios de imitação da terceira dimensão, que ultrapassa o efeito do real e instaura a dúvida quanto a possibilidade desse objeto ser real ou não. Na pintura (Figura 2), os objetos não têm referência, se mostram descontextualizados, são velhos jornais, livros, tábuas, restos alimentares, todos isolados e decaídos. Algo com uma vida anterior ao sujeito e à sua tomada de consciência. Tudo é artefato. Não há paisagem, rosto ou luz natural. 


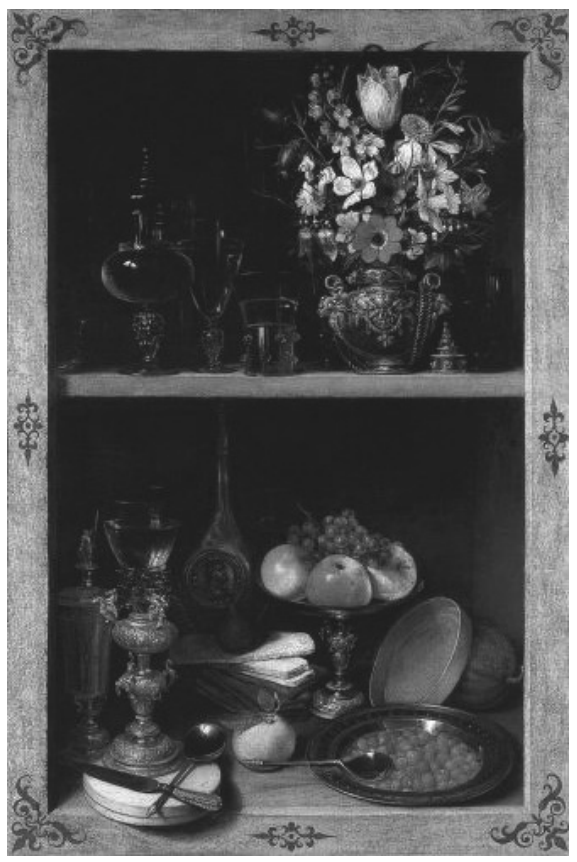

Figura 2 - George Flegel. Trompe l'oeil, 1610. Galerie Nationale, Praga.

Assim há uma descaptação do real pelo excesso das aparências do real. Os objetos se parecem demais com o que são (observar a figura 2). Tal "semelhança é como um estado segundo, e seu verdadeiro relevo, através dessa semelhança alegórica, através da luz diagonal, é o da ironia do excesso de realidade" (Baudrillard, 1997, p. 18).

Tal efeito é obtido, segundo Baudrillard, pois a profundidade é invertida. Enquanto no Renascimento a linha de fuga está em profundidade, no trompe-l'oeil o efeito de perspectiva é projetado para frente.

Enquanto os objetos fogem panoramicamente diante do olho que os varre (privilégio de um olho panóptico), são eles aqui que "enganam"(trompent) o olho por um espécie de relevo interior - não porque levassem a crer num mundo real que não existe, mas por frustrarem a posição privilegiada de um olhar. O olho, em vez de ser gerador de um espaço reduplicado, não passa de um ponto de fuga interior à convergência dos objetos. Um outro universo se escava em direção à frente - não há horizonte, não há horizontalidade, trata-se de um espelho opaco erguido diante do olho, e não há nada atrás. Esta é propriamente a esfera da aparência - nada a ver, são as coisas que nos vêem, elas não fogem à sua frente, dirigem-se para a sua frente, com essa luz que lhes chega de outro lugar, e essa sombra induzida que não lhes dá, no entanto, jamais uma verdadeira terceira dimensão. (Baudrillard, 1997, p. 19)

O trompe-l'oeil subtrai uma dimensão dos objetos reais e torna sua presença mágica. Permite reencontrar o sonho, irrealidade total na sua exatidão minuci- osa, "êxtase do objeto real em sua forma imanente, é o que acrescenta ao encanto formal da pintura, o encanto espiritual do engano, da mistificação dos sentidos" (Baudrillard, 1997, p. 82).

O que as imagens publicitárias guardam do trompe-l'oeil? Observando a "imagem" (Figura 3), podemos dizer que ela nos contempla, chama nossa atenção, incita-nos a fazer silêncio. É ela que nos olha, que se dirige à nossa frente e que nos faz crer que está ali e sutilmente nos convida a adentrar a selva. Leva-nos a responder: "Mas estou em silêncio [...]". Deste modo, guarda da pintura mencionada o fato de chamar a atenção do leitor e se por diante dele.

A questão de roubar dimensões da realidade pode não ser comum a todas as peças da publicidade impressa, no entanto, a "imagem" guarda da pintura mencionada o fato de chamar o olhar do leitor e se por diante dele.

Há imagens elaboradas com as técnicas da pintura trompe l'oeil que nos encantam, mas há as que desencantam.

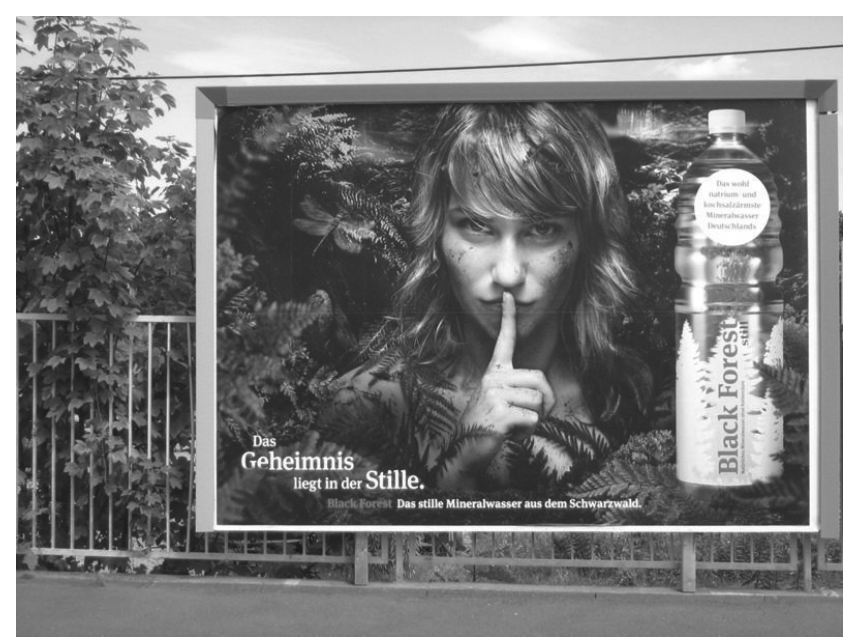

Figura 3 - "Ouça a natureza"2

O máximo do simulacro, segundo Baudrillard, mais verdadeiro que o verdadeiro, é a pornografia. O pornô "acrescentando uma dimensão à imagem do sexo, subtrai a dimensão do desejo, e desqualifica toda ilusão sedutora" (1997, p. 82). Há imagens publicitárias que se aproximam desse máximo. São Paulo, antes da lei "Cidade Limpa", estava invadida por tais imagens (Figuras 4 e 5) $)^{3}$.

"No pornô, nada deixa mais a desejar" (Baudrillard, 1997, p. 106). O autor explica que depois da orgia e da liberação de todos os desejos, com a transparência do sexo por meio de signos e imagens, ele perde o segredo e a ambiguidade, dando lugar ao transexual. A cena 
do desejo, a cena da ilusão dá lugar à obscenidade transexual. "Na realidade, não há mais pornografia referenciável enquanto tal, porque a pornografia está virtualmente em toda parte, porque a essência do pornográfico repassou todas as técnicas do visual e do televisual." (Baudrillard, 1997, p, 107).

Baudrillard conjetura que talvez façamos representar a comédia do pornô na publicidade obscena das

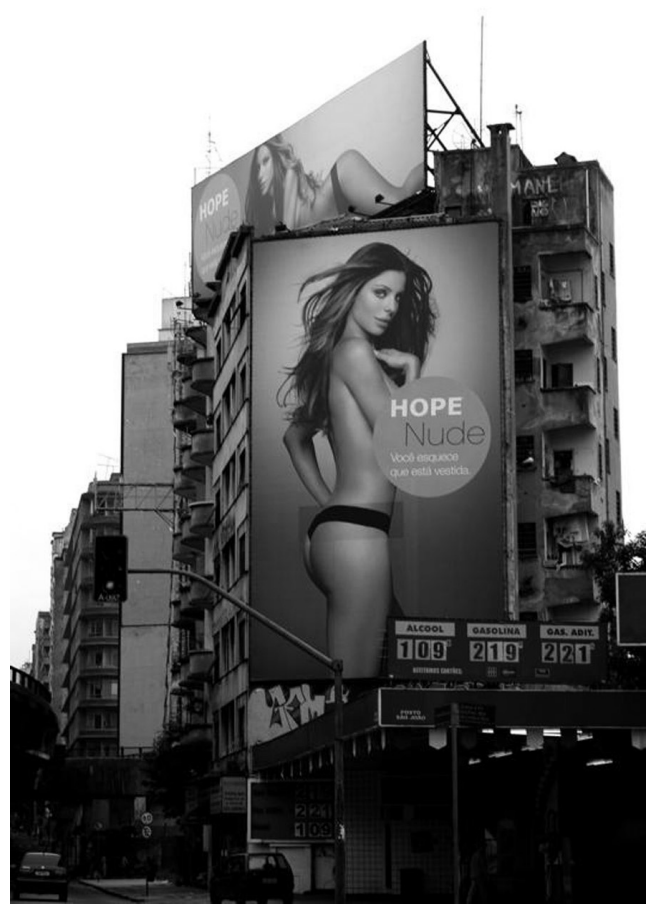

Figura 4 - "Perseguição"

Mas o que se dá com as imagens televisivas, as cinematográficas e as sintéticas? Para Baudrillard (1997, p. 80), o cinema no decorrer das transformações técnicas - do filme mudo ao falado, da cor, ao alto tecnicismo dos efeitos especiais-, perdeu a ilusão, contudo, para o autor, a ilusão não se contrapõe ao real, mas constitui uma realidade mais sutil que envolve o real como signo da desaparição. As imagens cinematográficas perderam suas especificidades de modo que se aproximam das televisivas. Elas se tornaram excessivamente técnicas e velozes e deste modo há ausência de branco, de vazio, de elipse e do silêncio.

Enquanto isto as imagens televisivas caminham para a alta definição, o que para o autor corresponde à perfeição inútil da imagem. "Que por causa disso não é mais uma imagem, de tanto que se produziu em tempo real. Quanto mais chegamos perto da definição absoluta, da perfeição realista da imagem, mais se perde o poder da ilusão" (Baudrillard, 1997, p. 81) imagens do corpo feminino e que se tudo isso fosse verdade-os strip-teases incessantes, as fantasias de sexo explícito, a chantagem sexual - seria realmente insuportável. Mas não haveria nessa ironia do pornô um mistério em filigrana? Pergunta o autor. O sexo ri de si mesmo em sua forma mais exibicionista, a ironia. "A ditadura das imagens é uma ditadura irônica" (1997, p. 108).

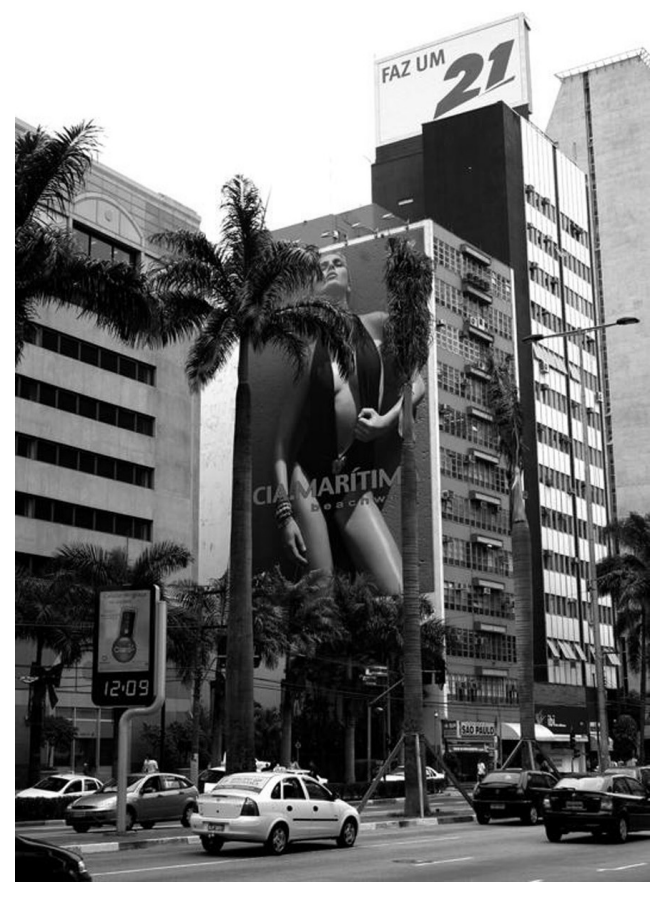

Figura 5 - "12:09...toda hora...é hora!"

A imagem sintética, a imagem numérica, a realidade virtual corresponde ao apogeu da 'desimaginação' da imagem. A virtualidade, ao nos fazer adentrar na imagem, recria uma imagem em três dimensões e abole a ilusão do passado e do futuro, por se dar em "tempo real". Instaura, segundo o mesmo autor, a ilusão perfeita, recriadora, mimética. Extermina o real, determina a morte dos sentidos, pelo seu duplo.

Baudrillard adverte que desaprendemos com relação à modernidade, "que é a subtração que dá força, que da ausência nasce o poder" (1997, p. 83). As imagens se acumulam, se adicionam, se inflacionam. Não somos "mais capazes de encarar o domínio simbólico da ausência, por isso é que nos encontramos hoje em dia mergulhados na ilusão contraditória, aquela desencantada da profusão, a ilusão moderna da proliferação das telas e das imagens" (Baudrillard, 1997, p. 83).

Para o autor, na realidade virtual as coisas se tornam transparentes, sem segredos, ou seja, não criam 
mais ilusão, no entanto, ganham ironia. "Sucede à função crítica do sujeito a função irônica do objeto, ironia objetiva e não subjetiva." (Baudrillard, 1997, p. 93)

A partir do momento em que elas são produtos fabricados, artefatos, signos, mercadorias, as coisas exercem uma função artificial e irônica por sua própria existência. Não é mais necessário projetar a ironia no mundo real, não é mais necessário o espelho exterior oferecendo ao mundo a imagem do seu duplo: nosso universo engoliu seu duplo, tornouse, portanto, espectral, transparente, perdeu sua sombra, e a ironia desse duplo incorporado explode a cada momento, em cada fragmento de nossos signos, de nossos objetos, de nossas imagens, de nossos modelos (Baudrillard, 1997, p. 93).

Assim, como explica o autor, as coisas, privadas de seu segredo e de sua ilusão, estão condenadas à existência, à aparência visível, estão condenadas à publicidade, a se tornar públicas. "Todas as coisas querem hoje em dia manifestar-se. Os objetos técnicos, industriais, midiáticos, os artefatos de todas as espécies querem significar, ser vistos, ser lidos, ser gravados, ser fotografados" (Baudrillard, 1997, p. 94) e tais objetos objetos-fetiches -, sem significação, sem ilusão, sem valor seriam o espelho da nossa desilusão radical do mundo.

\section{A era da lógica paradoxal da imagem se inicia com a invenção da videografia, da holografia e da infografia como se, neste final do século XX, a própria conclusão da modernidade fosse marcada pelo encerramento de uma lógica da representação pública.}

As imagens e a questão da velocidade que elas adquirem devido às tecnologias, que constroem uma nova lógica, são aspectos tratados por Virilio. Para esse autor (2002, p. 35), no Ocidente, a morte de Deus, a morte da arte e o grau zero da representação estão vinculados e vão ao encontro da máxima de Nicéforo (patriarca de Constantinopla, durante a disputa iconoclasta), feita há mil anos: "Se suprimirmos a imagem, desaparece não somente o Cristo, mas o universo inteiro" (Virilio, 2002, p. 35).

Segundo esse mesmo autor, na publicidade para se abrir mão da mensagem - da palavra -, em favor da imagem, as palavras-chave dos cartazes são impressas em uma cor cuja luminosidade é a mesma do fundo em que as mesmas se inscrevem, com a divergência entre o focalizado e o contexto e entre a imagem e o texto. Isto para que o leitor leve mais tempo para decifrar a mensagem escrita ou abandoná-la em detrimento da imagem.

A imagem fática, denominação dada por Virilio para a imagem-alvo que força o olhar e prende a atenção, não é somente resultado de focalizações cinematográficas e fotográficas, mas também o resultado de uma iluminação cada vez mais intensa e da intensidade de sua definição que só restituem zonas específicas, com o contexto desaparecendo na maior parte do tempo em meio à onda.

Mas qual a lógica que subjaz às imagens? Segundo Virilio (2002, p. 91), a era da lógica formal da imagem, a da pintura, da gravura e da arquitetura, terminou no século XVIII. A era da lógica dialética, a da fotografia, da cinematografia ou, se preferir, do fotograma, no século XIX. A era da lógica paradoxal da imagem se inicia com a invenção da videografia, da holografia e da infografia como se, neste final do século XX, a própria conclusão da modernidade fosse marcada pelo encerramento de uma lógica da representação pública.

O autor explica que conhecemos bem a realidade da lógica formal da representação pictural tradicional e, em algum nível mais baixo, a atualidade da lógica dialética que preside a representação fotocinematográfica, no entanto, estimamos com dificuldade as virtualidades da lógica paradoxal do videograma, do holograma e da imagerie numérica.

O paradoxo lógico, o da imagem em tempo real, domina a coisa representada. Trata-se de um tempo que se impõe ao espaço real. A virtualidade domina, portanto, a atualidade, ou ainda, subverte a própria noção de realidade. Daí esta crise das representações públicas tradicionais (gráficas, fotográficas, cinematográficas...) em benefício de uma apresentação, de uma presença paradoxal, telepresença a distância do objeto ou do ser que supre sua própria existência aqui e agora. É esta, finalmente, a alta definição, a alta resolução 
não tanto mais da imagem (fotográfica e televisiva), quanto da própria realidade.

Com a lógica paradoxal, na verdade, é a realidade da presença em tempo real do objeto que é definitivamente resolvida, ao passo que na era da lógica dialética da imagem precedente era somente a presença em tempo diferenciado, a presença do passado que impressionava duravelmente as placas, as películas ou os filmes, a imagem paradoxal assumindo assim um comportamento comparável ao da surpresa, ou ainda mais precisamente, do "acidente de transferência"(Virilio, 2002, p. 91-92).

Para o mesmo autor (Virilio, 2002, p. 94), na televisão só pode haver surpresa, não há tempo para o suspense. Esta é a lógica paradoxal do videograma, que privilegia o acidental, a surpresa, em detrimento da substância durável da mensagem, lógica dialética do fotograma, que valoriza de uma vez a extensividade da duração e a ampliação da extensão das representações.

A infografia e a holografia materializam figuras impossíveis de se ver de outra forma. Na primeira, a imagem perde uma dimensão - de três passa a ter duas -, enquanto na segunda o relevo é exterminado, ou seja, não há mais a perspectiva da profundidade. A televisão ao vivo, por exemplo, trabalha com o relevo, com a profundidade de campo de espaço real.

Segundo Virilio (1993), o enquadramento na tela do computador, do ponto de vista dos projetistas, difere do dos espectadores e telespectadores e também dos quadros de referência da representação gráfica e fotográfica, "na medida em que contêm todos eles, unidos em uma interface, em uma "comutação da visão" que impossibilita qualquer distinção normativa entre o real e o simulado" (p. 89).

Compreender a lógica que subjaz à "produção" das imagens é o diferencial das ideias de Virilio, no entanto, a questão real/virtual ainda é problemática.

Para concluir esta introdução, tomamos ideias de Jameson (2006). O autor distingue, no século XX, três momentos no que ele denomina de "teoria da visão", que depende da elaboração histórica de uma cultura social e de uma experiência social da visão que posteriormente se teoriza. Os momentos são os seguintes: colonial, burocrático e pós-moderno. O primeiro, resumidamente, dá-se "em torno do fenômeno protopolítico frequentemente caracterizado como dominação [...]. Transformar os outros em coisas através do olhar passa a ser fonte protopolítica da dominação" (Jameson, 2006, p. 129).

No segundo momento, o visível, principalmente pelas posições de Foucault, segundo Jameson, "passa a ser um olhar burocrático que busca a mensurabilidade do outro e do seu mundo, doravante reificados" (Jameson, 2006, p. 130). O ponto máximo deste momento está naquele que "o ver se combina com a mediação e o saber termina por envolver os meios de comunicação em uma metamorfose notável da própria imagem" (Jameson, 2006, p. 134).

Quanto ao terceiro momento, o verdadeiro momento da sociedade da imagem ou avatar da visualidade, apresenta problemas paradoxais à medida que a completa estetização da realidade se dá com a colocação mais completa em imagem dessa mesma realidade.

Assim, compreender a relação entre imagem e cognição é uma questão imprescindível. Neste sentido, não para dar conta dessa problemática, mas para refletir sobre as ideias mencionadas, que fazem parte das investigações que envolvem processos comunicacionais e as mídias, buscamos a semiótica peirceana. A seguir alguns aspectos que consideramos relevantes para compreender a relação entre imagem e cognição.

\section{Imagem e cognição}

Na semiótica, as representações são signos e as operações mentais se dão como processos sígnicos. Inicialmente vejamos como as representações visuais podem preponderar como índice ou hipoícone - no caso, hipoícone-imagético -, ou seja, vamos estabelecer se nesse movimento entre níveis de iconicidade e de indexicalidade o pensamento pode fluir.

Segundo Santaella e Nöth (2001, p. 59-62), há três níveis de iconicidade: ícone puro, o atual e o signo icônico ou hipoícone. O ícone puro é reino absoluto das qualidades, com ausência de tempo e de cognição, consciência de qualidade. $\mathrm{O}$ ícone atual, que se divide em ativo e passivo, diz respeito à sua atualidade e se refere às diferentes funções que o ícone adquire nos processos de percepção. São signos icônicos ou hipoícones - signos que representam seus objetos por semelhança -, e são subdivididos em imagem, diagrama e metáfora. A inclusão da imagem se dá porque a qualidade de sua aparência é considerada semelhante à qualidade da aparência do objeto que a imagem representa. No âmbito das imagens propriamente ditas, a representação se mantém em nível de mera aparência e são qualidades primeiras - forma, cor, textura, volume, movimento ou uma mistura delas -, que entram em relações de similaridade e comparação, tratando-se, portanto, de similaridades na aparência.

Mas as imagens que compõem o cenário cotidiano se apresentam como existentes, com materialidade e aqui e agora; logo, também podem funcionar como sig- 
nos por estabelecerem uma conexão de uma coisa com outra. $\mathrm{O}$ índice também está impregnado de qualidades, no entanto "não é em razão dessas qualidades que o índice funciona como signo, mas porque nele o mais proeminente é o seu caráter físico-existencial, apontando para outra coisa (seu objeto) de que ele é parte" (Santaella, 1983, p. 67).

Assim as representações visuais, à medida que captam traços do real, tendem a prevalecer como índices. As imagens televisivas, as imagens publicitárias, algumas modalidades de imagens sintéticas perdem níveis de iconicidade e oscilam entre hipoícone (imagem) e índice.

\section{0 que chamamos uma coisa é um conglomerado ou hábitos de reação, ou, para usar uma frase mais familiar, é um centro de forças.}

Quanto ao efeito do interpretante, pelo fato de que há similaridade na aparência, a operação mental envolvida é a analogia e ela se dá ao nível das qualidades. Na esteira de Perelman (2005, p. 424 -425), uma analogia é constituída de duas partes: tema e foro, com dois termos em cada uma. Sejam A e B os termos do tema e C e D, os do foro. O valor argumentativo de uma analogia pode ser posto em evidência se a tomarmos como uma similitude de estruturas, cuja fórmula é a seguinte: A está para $B$ assim como $C$ está para $D$, ou ainda, A : B :: C : D. Sobre o tema repousa a conclusão e sobre o foro se assenta o raciocínio. Assim, o foro é mais conhecido que o tema cuja estrutura ele deve esclarecer. Os exemplos ou simples ilustrações são casos particulares de analogias, que ocorrem quando tema e foro pertencem à mesma área.

Ainda na esteira da mesma autora (Santaella, 1983, p. 425), tomemos um exemplo dado por Aristóteles: "Assim como os olhos dos morcegos são ofuscados pela luz do dia, a inteligência da nossa alma é ofuscada pelas coisas mais naturalmente evidentes."

Sistematizemos a analogia, exibindo os termos do foro e do tema.

inteligência da alma : evidência : : olhos de morcego : luz do dia
$\mathrm{Na}$ analogia acima e considerando o esquema "A: $B$ :: $C$ : D"; A corresponde a "inteligência da alma"; B, a "evidência"; C, a "olhos de morcego e D, a " luz do dia" .

Nas analogias há aproximação entre os termos do foro e do tema que conduz a uma inteiração, bem como há valorização ou desvalorização dos termos do tema. No exemplo há uma valorização, uma vez que todas as pessoas pressentem o forte efeito da luz do dia para os olhos do morcego. A analogia pode também ser construída com três termos, como o esquema: A está para $\mathrm{B}$, assim como A está para $\mathrm{C}$.

Como exemplo, tomemos a figura 3. Algumas analogias possíveis::: Frescor : Água Mineral :: Frescor : Selva e Suavidade : Água Mineral :: Suavidade : Mulher Assim, a água mineral propicia frescor e é suave.

Nesse exemplo, esboçamos a analogia, no entanto, na mente do leitor ela não se dá no nível da consciência autocontrolada, mas no da consciência dual, que se dá pela experiência do confronto, da percepção. Como ela é permeada pela primeiridade, as qualidades atreladas às cores, às texturas ou outros aspectos que exalam ou provém do representamen (o que é capturado pela mente do leitor, de algum modo, a partir do que lhe é externo) são modificadas pela consciência em qualidades de sentimento.

Assim se ao contemplar e atentar para a imagem (figura 3), as qualidades que emanam do jogo de cores - tons esverdeados e um branco esfumaçado -, podem ser convertidos pela consciência do leitor em frescor, suavidade. Também a "mulher" que emerge em meio ao verde, ninfa - deusa dos rios, das selvas - , mulher jovem e formosa, com cabelos que se retorcem e se misturam entre as folhas verdes e olhar felino, vem impregnada de suavidade ao pairar silenciosamente por entre o verde e, ao mesmo tempo, vem como portadora de forças da natureza atreladas à água, à selva. Essas qualidades podem ser transferidas para a água, por analogia. Este tipo de operação mental vem com "imagens" que ao afetar a mente do leitor deslizam de sin-signos indiciais para sin-signos icônicos, de certo modo, são imagens que primam pelos aspectos qualitativos ou potencializam o poder de sugestão. Nos exemplos, figuras 3, 4 e 5, a primeira tem maior poder de sugestão que as outras.

Caso a "imagem" prevaleça como índice, o efeito é um dicente. Constatação. Segundo Peirce, o signo dicente veicula informação e corresponde à categoria lógica da proposição, que consiste de uma combinação de pelo menos um argumento (sujeito) e de um predicado. É o que se dá em "A é B". O tempo do usu- 
ário não flui, uma vez que não se desencadeia uma semiose genuína, predomina a consciência dual, do embate.

O signo que estabelece relações diádicas entre o representamen e o objeto - relações que têm o caráter de casualidade, temporalidade e espacialidade-, o índice, pode ser compreendido quando posto em comparação com outros signos. Nas palavras de Peirce:

Os índices podem distinguir-se de outros signos ou representações por três traços característicos: primeiro, não têm nenhuma semelhança significante com seus objetos; segundo, referem-se a individuais, unidades singulares, coleções singulares de unidades ou a contínuos singulares; terceiro, dirigem a atenção para os seus objetos através de uma compulsão cega (...) Psicologicamente, a ação dos índices depende de uma associação por contiguidade e não de uma associação por semelhança ou por operações intelectuais (CP 2.306).

No caso das peças publicitárias, as imagens podem prevalecer como índices ao clamar a atenção para os seus objetos, via compulsão cega, tal como as imagens das figuras 4 e 5 , como exemplos.

Por outro lado, a cognição está vinculada às qualidades de sentimento, ou ainda, ela se estabelece e se sustenta quando tais qualidades se atualizam e assim constroem um tecido qualitativo denso para a cognição fluir.

Ainda para entender a relevância das qualidades de sentimento nas conexões das ideias, mencionamos os modos de associação das ideias. Segundo Peirce, dizer que as ideias são similares, apenas pode significar que um poder oculto das profundezas da alma nos força - quando elas já não estão presentes - a conectálas nos nossos pensamentos. Há dois princípios de associação: a contiguidade e a similaridade, o primeiro é uma conexão devida a um poder externo, enquanto que o segundo é uma conexão devida a um poder interno.

O poder interno se constitui com as qualidades de sentimento que potencialmente podem se atualizar. Se uma qualidade de sentimento está presente por ser intrínseca a uma ideia, então, potencialmente há uma quantidade não enumerável de outras qualidades, que desta diferem por infinitesimais, que tendem a se atualizar. O poder externo às ideias pode ser atribuído ao poder de conexão que elas estabelecem entre elas, independente da mente que afetam, independente da história de semioses do sujeito ou de seu mundo interior.

Ainda sobre o poder interno e o poder externo, Peirce explica que a associação interior se baseia nos hábitos do mundo interior, enquanto a associação externa se baseia nos hábitos do universo. Segundo o mesmo autor, uma qualidade de sentimento é tal como é ela própria, sem qualquer elemento ou relação. Por exemplo, uma forma de vermelho não lembra outra forma de vermelho e quando mencionamos uma forma de vermelho, já não é de ideias de sentimento que estamos falando, mas de um conglomerado delas. Assim, o conglomerado delas junto no mundo interior constitui o que apreendemos e nomeamos como lembrança delas. Sendo nossas mentes consideravelmente adaptadas ao mundo interior, então, as ideias de sentimento atraem umas as outras em nossas mentes, e, no curso da experiência desenvolvem conceitos gerais. As qualidades sensíveis são tais conglomerados. Daí nossa mente ser suscetível, como diz Peirce, a forças gentis.

As associações de nossos pensamentos baseados nos hábitos dos atos de reação são chamadas associações por contiguidade. Ser contíguo significa estar próximo no espaço e no tempo e o que conecta um lugar a ele próprio é um ato de reação. A mente, por seu instinto de adaptação ao mundo exterior, representa coisas no espaço, que é sua representação instintiva de aglomerar reações. O que chamamos uma coisa é um conglomerado ou hábitos de reação, ou, para usar uma frase mais familiar, é um centro de forças.

Por fim, ao buscarmos as ideias de Damásio, tentamos aproximar descobertas recentes da neurobiologia à construção teórico-experimental de Peirce sobre a relação entre pensamento - autocontrolado ou não - e qualidades de sentimento, uma vez que as suas constatações se davam em meio aos conhecimentos de biologia e da química do final do século XIX.

As investigações empreendidas por Peirce sobre a extensão espacial do sentimento envolviam o protoplasma. Uma porção de protoplasma poderia ser uma ameba ou um pedaço de lodo, que não diferia do conteúdo de uma célula nervosa, embora as suas funções pudessem ser menos especializadas.

Não existe dúvida que esse lodo ou ameba, ou qualquer porção do protoplasma que lhes seja similar, sente. Quer dizer, sente quando se encontra numa condição excitada. Observe-se como ela se comporta. Quando o todo se encontra quiescente e rígido, excitamos uma parte. Nesse ponto de excitação, começa a se desenvolver um movimento ativo, o qual gradualmente se difunde para outras partes. Nessa ação não se constata nenhuma unidade, nenhuma relação com o núcleo, tão pouco com qualquer órgão unitário. Trata-se de um simples continuum amorfo de protoplasma, com sentimento passando de uma parte a outra... (CP 6.133). 
A descrição continua em CP 6.133, porém o mais importante é enfatizar que Peirce constatou que o sentimento tem uma extensão objetiva, da qual vem ao encontro dos resultados das investigações de Damásio sobre o cérebro humano.

Segundo Damásio (1996), o cérebro e outras partes do corpo se encontram integrados por circuitos bioquímicos e neurais. Ele recebe sinais de outras partes do corpo e, também, de suas próprias partes. Há duas vias de interconexão entre o cérebro e as outras partes do corpo. Uma delas é a constituída por nervos motores e sensoriais periféricos que transportam sinais de todas as outras partes do corpo para o cérebro, e deste para todas as outras partes do corpo. A outra, a mais antiga em termos evolutivos, é a corrente sanguínea, que transporta sinais químicos, como os hormônios, os neurotransmissores e os neuromoduladores.

\section{Entre imagens e imagens que desfilam no cenário atual e} numa velocidade indescritível, há imagens pertinentes à imaginação, as que primam por aspectos qualitativos, que abandonam a redundância em detrimento de fendas.

Damásio (1996) relata resultados de pesquisas, envolvendo pacientes com lesões cerebrais, que reforçam a ideia de que os sistemas do cérebro identificados por desempenhar um papel importante no processamento das emoções também são necessários para a retenção de imagens mentais. Estas se encontram envolvidas nos processos da razão, no sentido lato do termo e, mais especificamente, ao se tomar decisões. Um subconjunto desses sistemas do cérebro está associado aos comportamentos de planejamento e de decisão nos âmbitos pessoal e social.

Deste modo, ao mencionarmos a analogia e a possibilidade de, por meio delas, avivarmos qualidades de sentimento, não mencionamos que há conexão de ideias ou semiose genuína. Há atualizações de qualidades de sentimento o que possibilita que elas se jun- tem em nossa mente e, no curso da experiência, como explica Peirce e como já mencionamos, levam ao desenvolvimento de conceitos gerais. Assim as analogias são benéficas para fundar semioses futuras.

Retomamos as ideias que compõem o cenário nas considerações finais.

\section{Considerações finais}

Sobre as idéias de Baudrillard podemos enfatizar que elas são coerentes, embora o autor explique que as imagens são "ocas de sentido", sob visão diferente da que defendemos. Segundo Noth", o autor "deplora a ausência do referente, do repetido, mas vê símbolo e não índice". Para Baudrillard o real foge, escapa pelo excesso de aparência do real. À luz das ideias peirceanas, explicamos que o "excesso de aparência do real" de imagens que permeiam nosso cotidiano nos leva à constatação, assim não possibilitam que semioses genuínas se desencadeiem. Prevalecem, portanto, como índices.

Quanto à lógica paradoxal mencionada por Virilio, essa pode estar vinculada à experiência do embate, do confronto. A imagem que se dá em tempo real, exatamente por essa "força", a do tempo real, faz com que elas prevaleçam como índices.

Quando ao aspecto de duplicar o real, dos simulacros ou ainda da virtualidade dominar a atualidade, segundo Baudrillard e Virilio, respectivamente, podemos dizer que estes aspectos predominam no meio acadêmico, se nos reportarmos à área de comunicação, pois a concepção de real desses autores mencionados não toma o possível como real. Assim a realidade ganha adjetivos e passa a ter nome composto. A ilusão do olhar, por meio de outras técnicas, vem agora com a "realidade aumentada". Em sendo o possível também real, o que podemos enfatizar é que as atualizações se dão em maior velocidade - pela presença de tecnologias, principalmente - e envolvem materialidades diferenciadas. $\mathrm{O}$ que antes tinha a materialidade referente ao pensamento atualizado em uma mente particular - do ser humano -, agora invade as telas do computador por exemplo. A virtualidade ou o universo das possibilidades cada vez mais é pensado por meio das suas infindáveis atualizações. Assim a virtualidade se faz presente e dá novas possibilidades para que a noção de realidade incorpore o universo do possível. Tal cenário possibilita a imaginação, como "capacidade de compor e decifrar imagens (Flusser, 1998, p. 24).

Por outro lado, se a imagem prevalecer como hipoícone imagético ou ícone atual, mesmo que semioses 
genuínas não se desencadeiem prontamente, a contribuição das 'imagens' para o pensamento pode ser ainda relevante. Os aspectos qualitativos atrelados às cores, às formas, às texturas ou a mistura desses aspectos deixa a mente ao caminhar de analogias, que propiciam o desenvolvimento de hábitos de sentimento nos agentes, logo, segundo as ideais peirceanas, propiciam também o caminhar de ideias, a conexão de ideias, de futuras semioses genuínas.

Assim entre imagens e imagens que desfilam no cenário atual e numa velocidade indescritível, há imagens pertinentes à imaginação, as que primam por aspectos qualitativos, que abandonam a redundância em detrimento de fendas.

Para Perelman (2005, p. 423), o único valor da analogia seria o de possibilitar a formulação de uma hipótese que seria verificada por indução, o que nos leva a enfatizar ainda mais a importância da analogia, uma vez que para Peirce, a formulação de hipótese está vinculada à abdução, tipo de raciocínio que leva ao original, ao novo, à criação o que exploraremos em outra oportunidade FAMECOS

\section{REFERÊNCIAS}

BAUDILLARD, Jean. A arte da desaparição. Rio de Janeiro: Editora UFRJ, 1997.

DAMÁSIO, Antonio. O erro de Descartes: emoção, razão e o cérebro humano. São Paulo: Companhia das Letras, 1996.

HARTSHORNE, C. \& WEISS, P. (vols. I-VI), 1959, e BURTS, A. W. (vols. VII-VIII), 1958. The Collected Papers of Charles Sanders Peirce. Harvard University Press, 1994. CD-ROM Intelex Corporation.

FLUSSER, Vilém. Ensaio sobre a fotografia. Lisboa: Relógio D'Água Editores, 1998.
JAMESON, Fredric. Espaço e Imagem. Rio de Janeiro: Editora UFRJ, 2006.

PERELMAN, Chäim; OLBRECHTS-TYTECA, Lucie. Tratado da argumentação: a nova retórica. São Paulo: Martins Fontes, 2005.

SANTAELLA, Lucia. O que é Semiótica. São Paulo: Brasiliense, 1983.

Matrizes da Linguagem e Pensamento. São Paulo:

Iluminuras, 2001.

SANTAELLA, Lucia. e NÖTH, Winfried. Imagem: Cognição, Semiótica, Mídia. São Paulo: Iluminuras, 2001.

VIRILIO, Paul. A máquina de visão. Rio de Janeiro: José Olympio, 2002.

\section{NOTAS}

*Este artigo se insere em reflexões envolvendo o projeto de pesquisa em desenvolvimento "Imagem e pensamento em cena", com o apoio da Fundação de Amparo à Pesquisa do Estado de São Paulo-FAPESP.

${ }^{1}$ Disponível em: <http://www.metmuseum.org/ explore/studiolo/studiolo.html>. Acesso em: 02 set.

2 Painel outdoor fotografado em Kassel (Alemanha), em julho de 2008, por Maria Ogécia Drigo (e-mail: maria.drigo@prof.uniso.br)

${ }^{3}$ Registro fotográfico realizado em dezembro de 2006, em São Paulo - antes da "Lei Cidade Limpa" -, por José Ferreira Neto (e-mail: jfsneto@hotmail.com).

${ }^{4}$ Observação dada por Winfried Nöth quando da discussão dessas ideias na $12^{\mathrm{a}}$ Jornada Peirceana do Centro Internacional de Estudos Peirceanos - CIEP , realizado na PUC/SP, em 18 de agosto de 2009. 